\title{
AUTOMATIC DOOR CLAMP RELEASER
}

\author{
S.M.Gowthaman ${ }^{1}$, J.Ramesh ${ }^{2}$ \\ ${ }^{1}$ Assistant professor, Mechanical Engineering, Knowledge Institute of Technology, Tamil Nadu, India \\ ${ }^{2}$ Assistant professor, Mechanical Engineering, Knowledge Institute of Technology, Tamil Nadu, India
}

\begin{abstract}
This Article is used to save the passengers inside the car in the time of major car crashes and accidents using simple technology. The main idea is to retrieve passengers during the time of accidents and crashes quickly. In the time of accident the door of the car is crushed due to the impact of the crash and the passenger inside is stuck, so in this situation instead of fixing the door permanently to the car it can be fixed temporarily so that the door can be easily removed from the car physically.
\end{abstract}

Keywords-Safety devices, Sensors, DC motor, Clamp holder, Center lock, ECU (Electronic Control Unit).

\section{INTRODUCTION}

According to the World Health Organization nearly 1.3 million people die in car crashes each year, on average 3,286 people are being subjected to accidents each day. The loss of life increases year by year. The result analysis has concluded that most accident happen due to rash driving particularly in highways. Engineers are trying their maximum to reduce the accidents, but there is a need to think what measures to take after the accident has happened to prevent such type of disaster's in future.

\section{EXISTING SYSTEM}

\subsection{Before Collision}

At present there are many safety devices and emergency precautions installed and modified in the car to minimize the accidents. Safety systems such as Hill start Assist Control (HAC), Active Roll Control (ARC), Kinematic Dynamic Suspension System (KDSS), Emergency Brake Assistance (EBA), Adaptive Cruise Control (ACC), Dynamic Laser Cruise Control (CLCC), Traction Control System (TCS), Lane departure prevention system, Assisted or Automated parking, Electronic Stability Programmer (ESP), Vehicle Dynamic Integrated Management (VDIM), Global Chassis Control (GCC), Pre-Crash Safety (PCS) .... Etc. These safety devices help the passenger to prevent the accident.

\subsection{After Collision}

Safety devices such as airbag (frontal airbags, side air bags, side tubular...), seatbelt, laminated wind shields, antiintrusion bars, pedestrian protection systems, cargo barriers (physical barriers), auto door lock release, these are the only safety systems which is used after collision, but there are partially functional for the passengers.

\subsection{Drawbacks}

But there are drawbacks, comparing to preventing accidents the safety precautions used after the accident is less. A real incident took place in los Santos, the passenger who is driving the car lock all the side doors by the center lock, unfortunately due to rash driving the car had crashed, the front body of the car is fully crushed and the doors of the car is heavily damaged. The passenger inside

The car is badly injured and unconscious in state, as the computer system in the car is malfunction the doors of the car could not be opened, a team of firefighters and rescue teams came to the accident site and try to retrieve the passenger from the car. But the body of the car is heavily damaged and the passenger inside the car is stuck. The rescue team used hydraulic pistons (tool used to cut heavy metal) and cut the door to retrieve the passenger from the damaged car, but it took 20minutes to retrieve the person from the damaged car.23 JAN 2014 - Same situation took place at Chicago; It took nearly four hours to retrieve the passenger from the car as the car was crushed badly.

As there is no useful safety mechanism for the passenger's protection, a new system can be introduced to improve in vehicle safety

\subsection{ADLCR}

In this type of situation the Automatic Door Clamp Releaser (ADCR) can be installed. The main idea is to instead of fixing the door permanently to the body of the car, it can be fixed temporarily by using a simple clamp holder and also a lock releasing mechanism to automatically release the door lock so that the door comes apart when it is being pulled.

\section{METHODOLOGY}

\subsection{Structure of Clamp Holder and Clamp}

The clamp holder is made up of metal, in which it is Ushaped. The size of the clamp holder will be slightly larger than the door clamp, it is made in U-shaped so that the door clamp will get inserted to it and placed at a suitable position as shown 


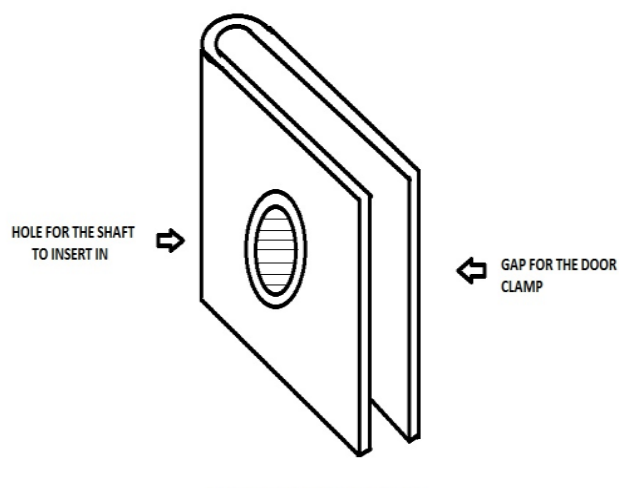

ISOMETRIC VIEW OF CLAMP HOLDER

Holes are made on side of the clamp holder where the opposite side of the clamp holder is fixed to the body of then car; the radius of the hole should be precisely equal to the radius of the holes in the door clamp so that the shaft in the DC motor can be inserted in the clamp holder easily. The below diagram shows the fixing of the door clamp to the clamp holder

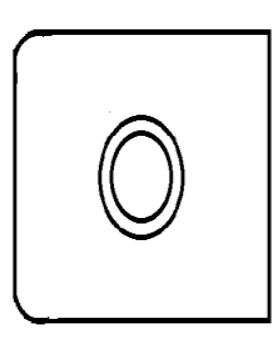

FRONTVIEW OF THE CLAMP HOLDER

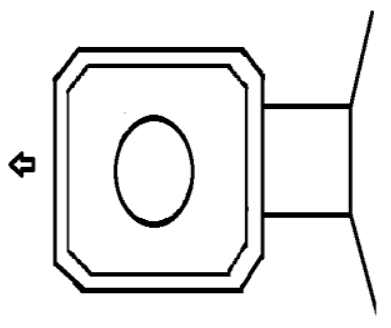

DOORCLAMP
DOOR CLAMP INSERTING INSIDE THE CLAMP HOLDER

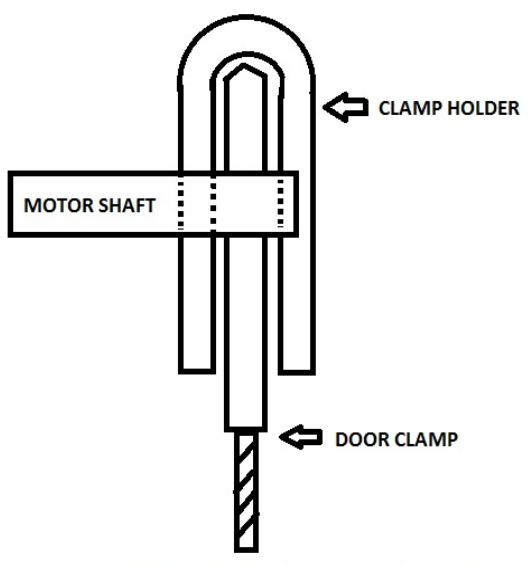

TOPVIEW OF THE CLAMP HOLDER AND DOOR CLAMP (MOTOR SHAFT FIXED POSITION)

When the door clamp is fixed to the clamp holder its top view will be as in the above figure. These is the setup for installing the ADCR, the DC motor shaft first spin forward and get fixed as shown in the above figure, this process is reversed at the time of accident.
The given block gives the process of the lock and clamp releaser

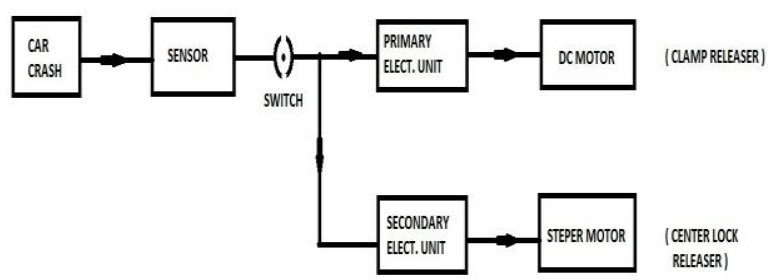

PROCESS OF ADCR IN THETIME OF COLISON

This given Block diagram gives a process description about the working of the Lock and the Clamp releaser.

\subsection{Sensor}

Sensors such as vibrational sensor (or) piezo-electric (or) crash sensor (or) impact sensor can be used.

The senor is used to detect and send electronic signals to the primary and secondary electronic unit when a collision has implemented. When a collision is implemented strong vibrations are being detected by the piezo-electric (or) vibrational (or) crash sensors. The sensors convert these vibrations into electrical signals and send to the primary and secondary electrical units. The sensor act as an initiating switch when collision occurs.

\subsection{Switch}

A switch is placed between the sensor and electrical units; it can be switched ON or OFF.

\section{PRIMARY ELECTRICAL UNIT}

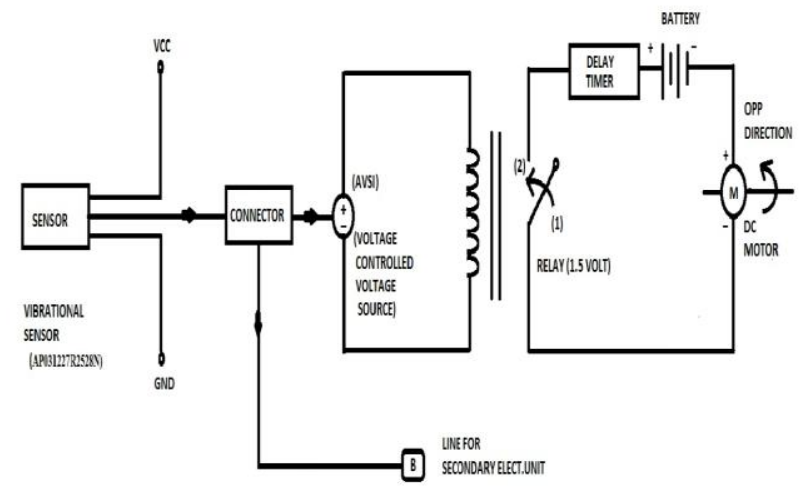

GRCUT DAGPAM FOR PRMARY ElECRRCAL UNT

When the car meets with an accident it feels a vibration, the vibration is sensed by vibration sensor and converts it into electrical signal, and the electrical signal is given to the Relay. 
Relay is an electromechanical device which converts this electrical signal to mechanical motion so that the switch closes as shown in the above figure. A delay timer is used in between the relay and the motor because when the accident occurs the vehicle needs to come at rest, so a minimum via $10 \mathrm{sec}$ is given to the timer, As soon as the switch closes delay timer starts, so that the motor will not rotate for few seconds. After a certain time limit (depending on the timer) the battery voltage will be given to the DC motor and the DC motor rotates in the anti-clockwise direction. The shaft of the DC motor will come in reverse direction so that the clamp can be released from the clamp holder.

In the above diagram a separate line will be given to the Secondary electrical unit (i.e.) the E.C.U system which alerts to unlock the door if it is in Locked position.

\section{SECONDARY ELECTRICAL UNIT}

In this unit, the idea is to unlock the door after few seconds the collision has indented. To unlocking system is being controlled by the Electronic Controlling Unit which is present inside the dash board of the car. At present there are many cars which unlock the door by changing the coding in the ECU. Therefore the Electronic Controlling Unit will automatically unlock the doors when a collision is implemented.

Most of the present cars have automatic lock releasing mechanism, cars like Audi Q3 series and BMW cars have these mechanisms, and this process is established by my making the stepper motor running in the reverse direction. When the stepper motor runs in the reverse direction it will unlock the door.

Both the lock and the door clamp have been released now the door can be pulled from the car and the passenger can be retrieved from the damaged car.

\section{CONCLUSION}

In order to remove the door a physical pulling is needed to remove the door from the car.

\section{REFERENCES}

[1]. Dr.Kirpal Singh-"Automobile engineering in a nutshell" - Safety devices www.standardpublishers.com ISBN: 98781-8014-172-0.

[2]. Falconi, D.R.Dept.of Electr. Eng., Univ. of Sao Paulo,Altafim, R.A.C. ; Altafim, R.A.P. ; Basso, H.C. ; Wirges, W. ; Gerhard-"Working of piezo-electric sensor". Page 1-3; year-2010; ISBN: 978-1-42244-7943-6.Publisher: IEEE.

[3]. Pimentel, J.C.G. ; Gad, E. ; Roy, S- "Stability analysis of DC motor speed controllers" Page 388 - 392; ISBN : 978-14244-3450-3; Publisher: IEEE.

[4]. Furukawa, Y. ; Kawamura, S- ECU-“Automotive electronics system“-Page-2; Year-2006; ISBN: 1-59593-370-

0. Publisher: IEEE.
[5]. Mulla Salim Husen, M.S. ; RIT, Islampur, India; Sanjay, D.Y. ; Shinde, D. ; Deshpande, G.-Center lock- Strength enhancement of 2010 Toyota Yaris Passenger Sedan driver seat as per Federal Motor Vehicle Safety Standards 207/210A FEA approach; Page 174 - 177 ; Year 2013; ISBN : 9781-4673-6149-1. 